\title{
Consciousness Regained: Disentangling Mechanisms, Brain Systems, and Behavioral Responses
}

\author{
- Johan F. Storm, ${ }^{1}{ }^{\circledR}$ Mélanie Boly, ${ }^{2,3}{ }^{\oplus}$ Adenauer G. Casali, ${ }^{4}$ Marcello Massimini, ${ }^{5,6}$ @Umberto Olcese, ${ }^{7,8}$ \\ (DCyriel M.A. Pennartz, ${ }^{7,8}$ and $\mathbb{D}^{\mathrm{C}}$ Melanie Wilke ${ }^{9,10,11}$ \\ ${ }^{1}$ Division of Physiology, Department of Molecular Medicine, Institute of Basal Medical Sciences, University of Oslo, Oslo, 0317, Norway, ${ }^{2}$ Department of \\ Neurology, University of Wisconsin, Madison, Wisconsin, 53705, ${ }^{3}$ Department of Psychiatry, University of Wisconsin, Madison, Wisconsin, 53719, \\ ${ }^{4}$ Institute of Science and Technology, Federal University of São Paulo, São José dos Campos, SP, 12231-280, Brazil, ${ }^{5}$ Department of Biomedical and Clinical \\ Sciences Luigi Sacco, University of Milan, Milan, 20157, Italy, ${ }^{6}$ Istituto Di Ricovero e Cura a Carattere Scientifico, Fondazione Don Carlo Gnocchi ONLUS, \\ 20162 Milano, Italy, ${ }^{7}$ Cognitive and Systems Neuroscience Group, Swammerdam Institute for Life Sciences and ${ }^{8}$ Research Priority Program Brain and \\ Cognition, University of Amsterdam, Amsterdam, 1098XH, The Netherlands, ${ }^{9}$ Department of Cognitive Neurology, University Medicine Goettingen, \\ Goettingen, 37075, Germany, ${ }^{10}$ German Primate Center, Leibniz Institute for Primate Research, Goettingen, 37077, Germany, and ${ }^{11}$ Leibniz Science Campus \\ Primate Cognition, Goettingen, 37077, Germany
}

How consciousness (experience) arises from and relates to material brain processes (the "mind-body problem") has been pondered by thinkers for centuries, and is regarded as among the deepest unsolved problems in science, with wide-ranging theoretical, clinical, and ethical implications. Until the last few decades, this was largely seen as a philosophical topic, but not widely accepted in mainstream neuroscience. Since the 1980s, however, novel methods and theoretical advances have yielded remarkable results, opening up the field for scientific and clinical progress. Since a seminal paper by Crick and Koch (1998) claimed that a science of consciousness should first search for its neural correlates (NCC), a variety of correlates have been suggested, including both content-specific NCCs, determining particular phenomenal components within an experience, and the full NCC, the neural substrates supporting entire conscious experiences. In this review, we present recent progress on theoretical, experimental, and clinical issues. Specifically, we (1) review methodological advances that are important for dissociating conscious experience from related enabling and executive functions, (2) suggest how critically reconsidering the role of the frontal cortex may further delineate NCCs, (3) advocate the need for general, objective, brain-based measures of the capacity for consciousness that are independent of sensory processing and executive functions, and (4) show how animal studies can reveal population and network phenomena of relevance for understanding mechanisms of consciousness.

Key words: brain complexity; consciousness; content-specific NCC; functional connectivity; neural correlates of consciousness; noreport paradigm; Perturbational Complexity Index; unresponsive wakefulness; vegetative state

\section{Introduction}

What is consciousness? How do our inner, subjective experiences fit into our scientific world view? Why does consciousness exist at

\footnotetext{
Received Aug. 21, 2017; revised Sept. 26, 2017; accepted Sept. 27, 2017.
}

This work was supported by European Union's Horizon 2020 Research and Innovation Programme under Grant Agreement 720270 (HBP SGA1) to M.M. who, with A.G.C., primarily wrote the section "Measuring brain complexity to detect (and promote) the recovery of consciousness"; C.M.A.P. and U.0., who primarily wrote the section "The conscious rodent brain: ensemble activity and long-range correlation patterns"; and J.F.S. who primarily wrote the "Introduction", the "Conclusions and perspectives" and the abstract, and edited the article; Hermann and Lilly Schilling Foundation, German Research Foundation WI 4046/1-1 and the Center for Nanoscale Microscopy and Molecular Physiology of the Brain to M.W., who primarily wrote the section "How to disentangle content-specific NCC from decision making and visuomotor processes"; National Institutes of Health/National Institute of Neurological Disorders and Stroke 1R03NS096379 to M.B., who primarily wrote the section "Are the neural correlates of consciousness mainly in the front or in the back of the cerebral cortex?"; São Paulo Research Foundation Grant 2016/08263-9 to A.G.C.; James S. McDonnell Foundation Scholar Award 2013, EU Grant H2020-FETOPEN-2014-2015-RIA 686764 Luminous, and Canadian Institute for Advanced Research, Azrieli Program in Brain, Mind and Consciousness to M.M.; FLAG-ERA JTC 2015 project CANON (cofinanced by The Netherlands Organization for Scientific Research) to U.0.; and the Norwegian Research Council to J.F.S. The authors M.B., A.G.C., M.M., U.O., C.M.A.P., and M.W. are listed alphabetically.

The authors declare no competing financial interests.

Correspondence should be addressed to Dr. Johan F. Storm, Division of Physiology, Department of Molecular Medicine, Institute of Basal Medical Sciences, University of Oslo, PO Box 1103 Blindern, 0slo, 0317, Norway. E-mail: j.f.storm@medisin.uio.no. all? Why are we not simply "zombies," responding to sensory input and producing behaviors according to the laws of nature, but with no subjective experiences?

Questions like these (the mind-body problem, mind versus matter, consciousness versus brain) have been pondered by thinkers for centuries, and are widely regarded as among the deepest unsolved problems in science, called "the ultimate intellectual challenge of this new millennium" (Dehaene and Changeux, 2004) and "the major unsolved problem in biology" (Crick, 2004) with wideranging theoretical, clinical, and ethical implications.

Until the last few decades, the fundamental problems of consciousness were largely regarded as philosophical, but not widely accepted as scientific topics in mainstream neuroscience. Thus, influential textbooks from that period contained little about these issues, and in the 46 previous annual meetings of the Society for Neuroscience (1969-2016) there have been few symposia explicitly focused on consciousness: a Society for Neuroscience 
satellite symposium on experimental approaches to consciousness chaired by Christof Koch (1998); and a minisymposium on the neural basis of consciousness chaired by Tsuchiya and Maier (2012). This is a paradox because the widespread interest in the brain surely stems much from its unique ability to generate our conscious experiences, including thoughts, feelings, and dreams. During much of the last century, the influential behaviorist school in psychology regarded "introspective" reports of subjective experiences as unscientific. Since the 1980s, however, pioneers have helped making consciousness a researchable, scientific topic; and novel methods and theoretical advances (e.g. the global workspace theory (GWT)/global neuronal workspace hypothesis, and the integrated information theory of consciousness (IIT)) have yielded remarkable results, opening up the field for scientific and clinical progress (Leopold and Logothetis, 2003; Owen et al., 2006; Seth et al., 2008; Dehaene and Changeux, 2011; Aru et al., 2012a; Casali et al., 2013; Hobson et al., 2014; Oizumi et al., 2014; Pennartz, 2015; Tsuchiya et al., 2015; Koch et al., 2016b; Tononi et al., 2016).

Nevertheless, some uncertainty and skepticism about the scientific status of this topic still remain, which may be seen as natural, given its exceptional methodological and philosophical challenges. Because the concept of consciousness is fundamentally derived from our subjective perspective, it seems hard to reconcile with science in general, which is based on objectivity, although certain aspects of experience are verifiable on an interpersonal basis. In addition, the many different concepts and meanings of the term "consciousness" remain a source of confusion. In this review, we focus on the most basic concept of consciousness: the existence of subjective experiences, (i.e., percepts, thoughts, dreams, imagery) that disappear in general anesthesia, coma, or certain stages of sleep (Dehaene and Changeux, 2011; Oizumi et al., 2014; Tononi et al., 2016). It is widely accepted that consciousness in this sense encompasses two main dimensions: (1) the "level" of consciousness (arousal/ wakefulness), largely controlled by the ascending activation systems of the brainstem and basal forebrain; and (2) the "content" of consciousness, thought to be largely represented by the thalamocortical system (Boly et al., 2013; Sanders et al., 2012; but for a critical review of "levels "of consciousness, see Bayne et al., 2016). Whereas arousal appears to be necessary for consciousness, it is not sufficient. Thus, brain-damaged patients can remain in a "vegetative" state of unresponsive wakefulness for years, with eyes open but no apparent signs of conscious content, leading to severe diagnostic and ethical problems. Thus, consciousness research spans from the deepest theoretical and philosophical questions to practical, experimental, clinical, and ethical issues.

Since the seminal paper by Crick and Koch (1998), which claimed that a science of consciousness should first search for its neural correlates (NCCs), a range of NCCs have been suggested in humans and animals. Recently, two varieties of NCC have been defined: (1) content-specific NCC determines a particular phenomenal component within an experience (e.g., a specific experience of a face), whereas (2) the full NCCs are the "neural substrates supporting conscious experiences in their entirety, irrespective of their specific contents" (Koch et al., 2016b). And as an alternative to the classic distinction between "content" and "level" of consciousness, the "level" may be regarded as reflecting "background conditions for being conscious," such as appropriate neuromodulatory input to "ensure adequate cortical excitability", whereas the content-specific and full NCCs are both seen as reflecting content of consciousness (Koch et al., 2016b). And now, after maturing for almost 30 years, the field reflects on its earlier findings, asking which of the reported NCCs truly represent consciousness and which are merely enabling factors or consequences (Miller, 2007; Dehaene and Changeux, 2011; Tsuchiya et al., 2015; Koch et al., 2016b; Tononi et al., 2016).

In the four sections in this review, we present recent progress on theoretical, experimental, and clinical issues. Specifically, we (1) review methodological advancements that are important for dissociating conscious experience from related enabling and executive functions, (2) suggest how critically reviewing the role of the frontal cortex may further delineate the NCCs, (3) advocate the need for general, objective, brain-based measures of the capacity for consciousness that are independent of sensory processing and executive functions, and (4) show how animal studies can reveal population and network phenomena of relevance for understanding mechanisms of conscious states.

\section{How to disentangle content-specific NCC from decision making and visuomotor processes}

A fruitful approach for finding correlates of visual consciousness has been the use of bistable visual stimuli, where the same physical stimulus gives rise to different percepts (Leopold and Logothetis, 1999) and perceptual suppression/masking paradigms where visual stimuli are erased from consciousness (Leopold and Logothetis, 1999; Kim and Blake, 2005; Dehaene and Changeux, 2011; Tsuchiya et al., 2015) (Fig. 1). In such paradigms, the difference between the trial-averaged neural activities from one perceptual state versus the other (e.g., "visible" vs "invisible") is typically considered to be a "neural correlate of visual consciousness" (NCC).

This approach identified NCCs in a wide range of brain regions and at different spatiotemporal scales, using diverse methods such as single cell, local field potential and EEG/MEG recordings as well as fMRI in monkeys and humans (Blake and Logothetis, 2002; Sterzer et al., 2009; Tsuchiya et al., 2015; Koch et al., 2016b). From these studies, the view has emerged that NCCs, measured as number of neurons and signal amplitudes that differentiate between two percepts, gradually increase from early stages of visual processing (i.e., LGN/V1) toward "higher-order" association areas and subcortical nuclei (i.e., V4/IT/frontoparietal cortices/thalamic pulvinar) (Boly et al., 2013). Electrophysiological studies in monkeys and humans revealed several signatures of visual consciousness, including a late and broadly distributed ERP component, called P3b and oscillations in $\alpha / \beta(9-30 \mathrm{~Hz})$ and $\gamma(>40 \mathrm{~Hz})$ bands within and between visual and frontoparietal cortices (Dehaene and Changeux, 2011). The multitude of brain regions and neural signals reported as "NCC" already suggests that they fulfill different functions in the process, leading to the critical question, which is now at the center of current debates in consciousness research (Aru et al., 2012b; Frässle et al., 2014; Tsuchiya et al., 2015; Koch et al., 2016b; Brascamp et al., 2018): which brain regions and signals previously reported as NCC constitute the content of visual consciousness, and which reflect either prerequisites (pre-NCC) or consequent decision and motor processes (post-NCC) that enable the perceptual report? To answer this question, researchers adopted several strategies, including the following: (1) refinement of behavioral paradigms allowing the dissociation between task demands and conscious stimulus processing; (2) development of no-report paradigms; (3) local inactivation and lesion studies; and (4) noninvasive brain stimulation techniques, such as transcranial magnetic stimulation (TMS) or direct/alternating current stimulation. Below we will summarize the latest develop- 
A

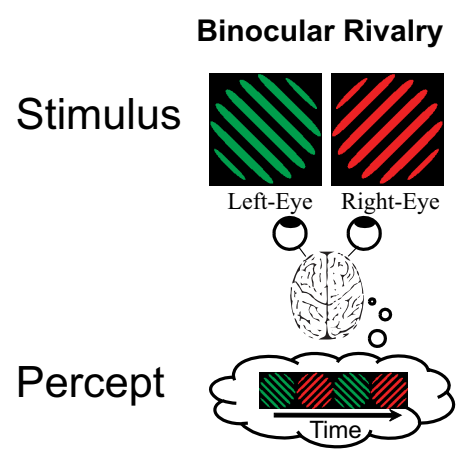

B

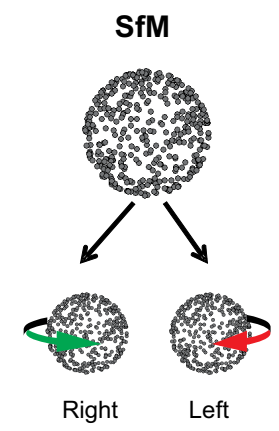

C

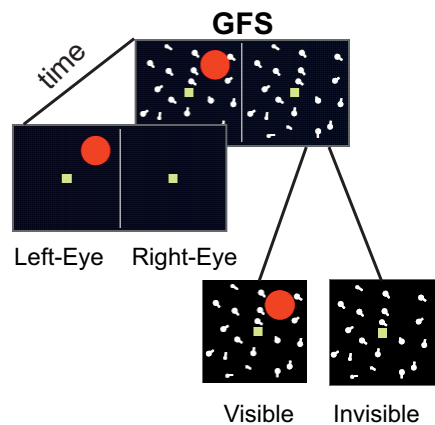

Figure 1. Examples of bistable stimuli. $\boldsymbol{A}$, In binocular rivalry, two stimuli are shown to different eyes and perception wavers between left and right eye stimuli (Blake and Logothetis, 2002). $B$, Ambiguous structure-from-motion (SFM) stimulus. Dots moving back and forth on a flat screen, without perspective cues to differentiate between front and rear surfaces, induce the perception of a 3D rotating object that periodically switches direction. (Sterzer et al., 2009) C, Generalized flash suppression. A target stimulus (red dot) is shown parafoveally followed by the onset of a moving surround, causing the red target to disappear in $\sim 50 \%$ of trials (Wilke et al., 2003).

ments for points 1-3 (for a review of noninvasive brain stimulation studies, see, e.g., de Graaf and Sack, 2014).

\section{Task refinements and No-report paradigms}

To study the neural basis of mental states, such as conscious contents, behavioral reports, such as button presses or eye movements, seem necessary. However, relying on overt responses confounds the putative NCC with other cognitive variables, such as selective attention, working memory, motor planning, and performance monitoring (Koch and Tsuchiya, 2012; Tsuchiya et al., 2015) (Fig. 2). Recent intracranial studies in the thalamic pulvinar and visual cortices in monkeys (Wilke et al., 2009) and an MEG study across visual cortices in humans (Kloosterman et al., 2015) have shown that the $\alpha / \beta$ power decrease typically associated with perceptual suppression vanishes when no behavioral report is required. By systematically varying task relevance and visual perception in a masking paradigm, a recent EEG study also came to the conclusion that the P3b ERP component might reflect a report-related post-NCC process (Pitts et al., 2014b). Similarly, recent fMRI studies in humans have shown that most frontoparietal BOLD activity changes related to perceptual switches during binocular rivalry vanish when task difficulty is held constant (Knapen et al., 2011) or without report when perceptual switches are inferred from involuntary physiological measures, such as pupil diameter and optokinetic nystagmus (Frässle et al., 2014). It needs to be noted that an apparent absence of percept-related prefrontal activation does not exclude its participation in sustaining visual consciousness since fMRI analysis relies on somewhat arbitrary thresholding. Indeed, there is evidence from single-cell recordings in monkeys showing imagespecific binocular-rivalry modulation in dorsolateral prefrontal cortex without a report (Panagiotaropoulos et al., 2012). Also, current no-report paradigms might be problematic because, for example, pupil size is also modulated by cognitive factors, such as decision uncertainty, reward prediction, and motor preparation; (Hupé et al., 2009; Laeng et al., 2012; Kloosterman et al., 2015; Overgaard and Fazekas, 2016) and seemingly "perception-related" optokinetic nystagmus during binocular rivalry is also observed in monkeys undergoing ketamine anesthesia (Leopold et al., 2002). Thus, albeit promising, the perfect no-report paradigm to study visual consciousness has not been developed yet, and evidence must be derived from orthogonal research approaches.

\section{Lesion and inactivation studies}

Human patients and monkeys with lesions in primary visual cortex (V1) are blind at the corresponding visual field location; therefore, the role of $\mathrm{V} 1$ as a prerequisite for visual consciousness seems unequivocal (Tong, 2003; Maier et al., 2008). However, the presence of "blindsight" (Stoerig and Cowey, 1997) (i.e., visually guided actions without accompanying visual consciousness) underlines that correct stimulus detection and localization do not necessarily implicate visual consciousness (Goodale et al., 1991; Cowey and Stoerig, 1995; Schmid et al., 2010; Sahraie et al., 2013; Ajina et al., 2015). On the other hand, the causal contribution of neural populations in area V1 (or LGN) as a possible substrate of conscious perception is difficult to evaluate in lesion studies because they also constitute prerequisites that might be subtracted out in the typical contrastive approach. Due to intact primary visual pathways, conscious perception is easier to evaluate in patients with higher-order thalamic, superior temporal, parietal, and frontal lesions, which often lead to impaired responses and exploration of the contralateral space called "spatial neglect" (Karnath, 2001; Kerkhoff, 2001; Karnath et al., 2002) (Fig. 3). However, biased spatial behavior can occur for different reasons, including impaired visual perception and/or motor decision/ planning deficits. Indeed, using a spatial decision paradigm with directed eye movements versus button presses showed that inferior parietal lesions in humans interfere with directed saccade choices but not with visual perception reported with button presses (Ro et al., 2001).

Similarly, by using local inactivation in specific parietal regions in monkeys (lateral intraparietal and medial intraparietal/ parietal reach region; Fig. 3), several studies showed effectorspecific visuospatial impairments (e.g., for hand but not eye movement reports and vice versa), which are hard to reconcile with the notion that the entire parietal cortex serves a critical function in visual consciousness (Hwang et al., 2012; Christopoulos et al., 2015; Katz et al., 2016). A similar case can be made for the dorsal pulvinar, which strongly interconnects with frontoparietal cortices. Spiking rates of pulvinar neurons in monkeys strongly correlate with reported perception (Wilke et al., 2009; Komura et al., 2013), but local inactivation and microstimulation there indicate visuomotor impairments with intact visual detection performance (Wilke et al., 2010, 2013; Dominguez-Vargas et al., 2017). However, pulvinar as well as parietal cortices might 


\section{A}

\section{Conceptual problem with visual consciousness studies}

\section{Observed correlation}

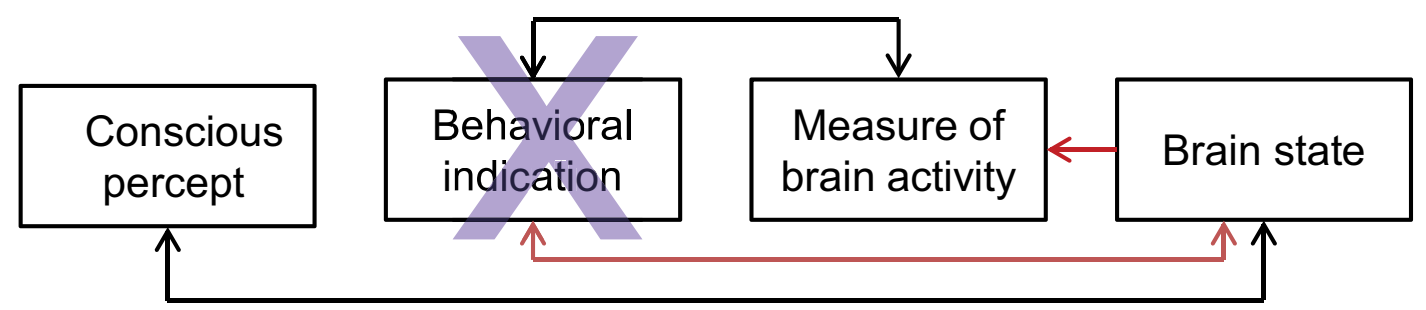

Correlation we are seeking

\section{B}

\section{Candidates for no-report readouts of conscious contents}

$$
\text { Pupil size }
$$

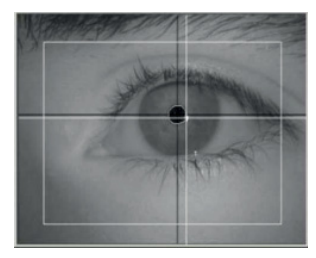

Optokinetic Nystagmus

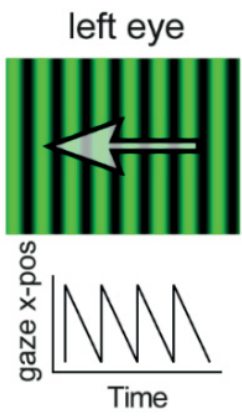

right eye
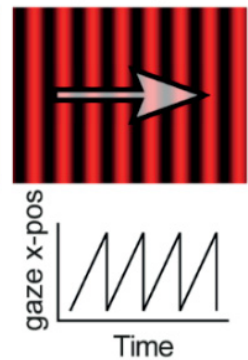
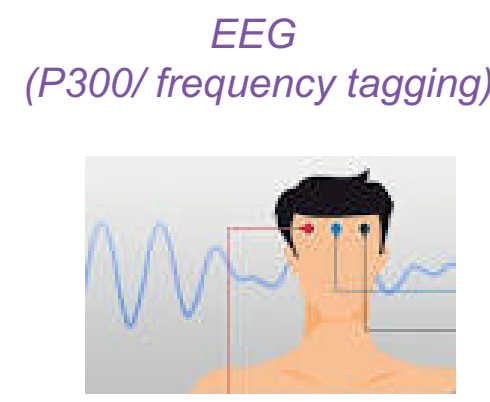

Figure 2. Experimental outline for the no-report paradigm for NCC studies. $A$, Depiction of the problem. We aim for the correlation between a conscious content and a given brain state. What is measured experimentally is the correlation between a behavioral report and a measure of brain activity, which might be appropriate or not. Report-related neural activity poses a confound for the NCC. B, Involuntary physiological measures taken to infer the perceptual state of a subject to circumvent the behavioral report (Tononi et al., 1998; Leopold et al., 2003; Laeng and Endestad, 2012; Tsuchiya et al., 2015).

contain subregions that are more closely related to visual consciousness as opposed to visuomotor behavior (Driver and Mattingley, 1998; Ward et al., 2002; Harvey and Rossit, 2012; Komura et al., 2013; Zhou et al., 2016). Thus, deciphering regional specificity and the further development and application of behavioral paradigms that allow the distinction between perceptual and action planning deficits will remain important. From the beginnings of NCC studies, it has been widely assumed that the prefrontal cortex plays a critical role in enabling both contents and levels of consciousness (Crick and Koch, 1998; Leopold and Logothetis, 1999; Cruse et al., 2011; Dehaene and Changeux, 2011). Because the role of the prefrontal cortex has recently emerged as one of the most controversial issues in NCC research (Pennartz, 2015; Koch et al., 2016a), the section below will review the recent correlative and lesion studies on the prefrontal cortex in more detail.

Are the neural correlates of consciousness mainly in the front or in the back of the cerebral cortex?

It has been widely assumed that prefrontal cortex is critical for consciousness as part of a frontoparietal network (Del Cul et al., 2009; Bor and Seth, 2012; Laureys and Schiff, 2012). However, recent evidence from lesion, stimulation, and neuroimaging studies challenges this assumption.
Lesion studies have provided several reports of patients with a normal level of consciousness after extensive frontal damage. For example, patient A (Brickner, 1952), after surgical removal of bilateral prefrontal cortex, once (sic) "toured the Neurological Institute" with "two [...] distinguished neurologists, [. . .] none of them noticing anything unusual until their attention was especially called to A" after more than an hour. By contrast, traumatic lesions of the posterior corpus callosum, connecting large parts of the posterior cortex, carry a 214-fold increased risk of permanent vegetative state (Kampfl et al., 1998). With regard to the contents of consciousness, there is no clear evidence for loss of specific experiential contents after frontal damage (Penfield and Jasper, 1954). Similarly, while lesions in frontal cortices have been reported to lead to overt visually guided orienting deficits, they hardly lead to impairments of conscious contents per se $(\mathrm{Na}$ et al., 1998; Mataró et al., 2001; Ro et al., 2001). In contrast, abundant neurological evidence points to lesions in the posterior cortex causing a loss of specific contents of experience (Farah, 2004). For example, lesions of the right fusiform face area may cause unconsciousness of faces, and lesions of inferolateral occipital cortex unconsciousness of colors (Barton, 2011).

Electrical stimulation of most of the frontal cortex fails to elicit content-specific changes in experience (Penfield and Jasper, 1954), although it can induce involuntary movements or interfere with 
A

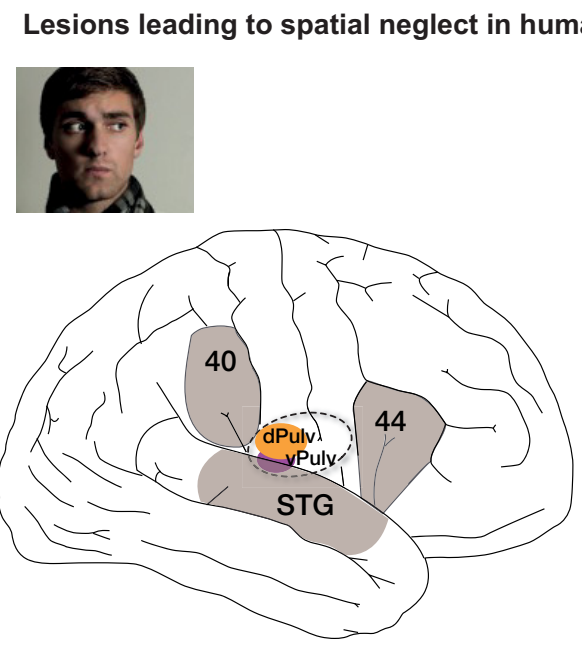

B

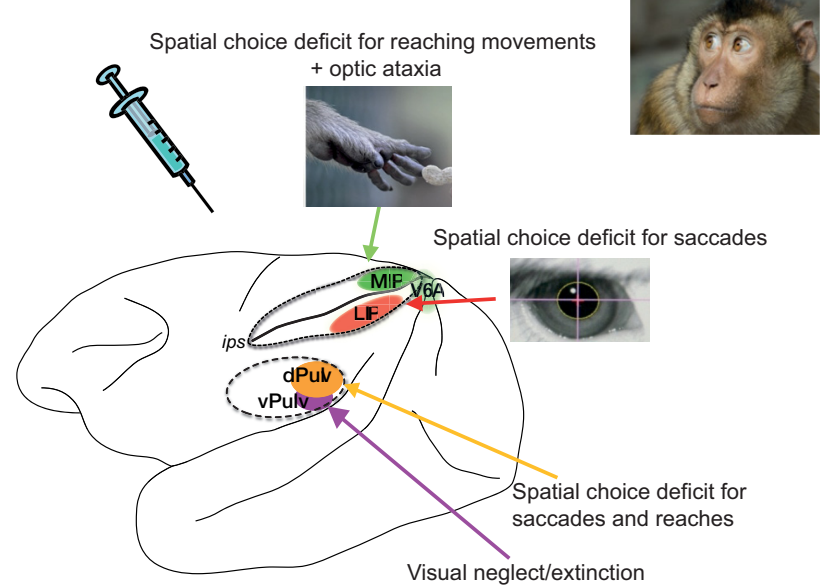

Figure 3. A, Major cortical and subcortical brain regions where lesions lead to spatial neglect in humans (left), and corresponding recent experimental results in monkeys (right) (lateral view). In humans, lesions in frontal (Brodmann area 44), inferior parietal cortex (Brodmann area 40), superior temporal gyrus (STG), basal ganglia, and pulvinar have been reported to lead to spatially biased behavior that might appear as a visual consciousness deficit (Karnath, 2001). B. Recent pharmacological inactivation studies in monkeys have shown primarily effector-specific spatial deficits after lesions in parietal subregions such as the lateral intraparietal area (LIP, red shading) and the parietal reach region (PRR, which includes the medial intraparietal area MIP and area V6A, green shading). Dorsal pulvinar (dPULV, orange shading) inactivation leads to spatial orienting bias for both eye and hand movements which can be compensated by visual reward cues, suggesting that visual perception might be preserved. Ventral pulvinar (vPULV, purple shading) inactivation leads to change detection deficits resembling visual neglect. Summarized from local inactivation studies in monkeys (Wardak et al., 2002; Wilke et al., 2010; Hwang et al., 2012; Wilke et al., 2012; Wilke et al., 2013; Hwang et al., 2014; Christopoulos et al., 2015; Katz et al., 2016; Zhou et al., 2016).

task performance (Selimbeyoglu and Parvizi, 2010). In contrast, electrical stimulation of posterior cortex more reliably induces discrete changes in conscious contents. For example, direct electrical stimulation of early visual areas induces phosphenes (Beauchamp et al., 2012; Winawer and Parvizi, 2016), whereas stimulation of the right fusiform gyrus selectively disrupts the perception of faces (Rangarajan et al., 2014).

Compared with lesion and stimulation studies, neuroimaging studies offer less direct evidence for the contribution of any one brain region to consciousness (Farah, 2004). However, neuroimaging experiments can demonstrate dissociations between the NCC and those of other cognitive processes (Aru et al., 2012b; de Graaf et al., 2012). For example, within-state, no-task paradigms, which avoid confounds due to behavioral state change and dissociate consciousness from behavioral responsiveness and task performance, have pointed to a parieto-occipital "posterior hot zone" as a reliable neural correlate of consciousness during sleep (Siclari et al., 2017). While studies comparing vegetative state patients to healthy volunteers highlighted differences in both frontal and parietal cortices and in thalamocortical connectivity (Gosseries et al., 2014), within-state approaches comparing minimally conscious to vegetative state patients show differences restricted to posterior cortex (Vanhaudenhuyse et al., 2010; King et al., 2013; Wu et al., 2015). In awake volunteers, studies using stimuli that are task irrelevant but experienced (thereby dissociating consciousness from cognitive functions involved in task demands; Aru et al., 2012b; de Graaf et al., 2012) identified content-specific NCC in posterior cortices during both inattentional blindness (Pitts et al., 2012) and backward masking experiments (Pitts et al., 2014a) irrespective of task relevance. In contrast, content-specific NCC at frontal recording sites (P3 component) was only found when the stimuli were task-relevant. As alluded in the previous section, "no-report" paradigms have also pointed to posterior regions as the NCC, whereas frontal cortex activation correlates with reporting (Tsuchiya et al., 2015; Koch et al., 2016b).
The advent of large-scale neuroimaging databases can now help to quantify systematic associations between specific conscious contents and the activation of specific cortical areas by using meta-analytic reverse inference (Poldrack, 2006; Yarkoni et al., 2010; Moran and Zaki, 2013; Poldrack and Yarkoni, 2016). In agreement with lesion and stimulation studies, reverse inference analyses performed, for example, with Neurosynth (www.neurosynth.org) locate the best predictors for specific conscious contents within specific areas of posterior cortex, such as the right fusiform face area for face percepts, occipital areas for visual words or motion, temporal areas for speech sounds, or parietal areas for touch percepts. In all these cases, reverse inference fails to highlight frontal areas as predictive for the presence of specific contents of consciousness (Boly et al., 2017).

Multivariate decoding techniques can also help to identify the true NCC as the brain activity patterns that have the highest predictive value for specific conscious percepts (Haynes, 2009; Sandberg et al., 2014). Using such approaches, the best predictor for the presence versus absence of consciousness has been located in temporo-parieto-occipital cortices both during non-rapid eye movement (NREM) sleep (Siclari et al., 2017) and in patients with brain damage (Demertzi et al., 2015; Stender et al., 2016). While studies comparing brain function during anesthesia versus wakefulness consistently highlighted differences in both frontal and parietal cortices and in thalamocortical connectivity (Alkire et al., 2008), activity in frontal regions was shown to be poorly predictive for the presence versus absence of connected consciousness (Gaskell et al., 2017). On the other hand, the predictive value of posterior cortex activity for consciousness during anesthesia still needs to be assessed (Boly et al., 2017). With regard to the contents of consciousness, numerous studies in both awake and dreaming subjects could decode the presence of specific conscious contents from specific activity patterns in posterior cortex (Nishimoto et al., 2011; Horikawa et al., 2013; Siclari et al., 2017), whereas the evidence for the frontal cortex is much less clear. 
Working memory contents can also be more reliably decoded from the back than from the front of the cortex (Emrich et al., 2013).

Together, evidence from lesion, stimulation, and neuroimaging studies consistently points to regions of the posterior cortex, including temporal, parietal, and occipital areas, as a "hot zone" for consciousness, in which different brain activity patterns may specify different experiential contents. By contrast, evidence for a content-specific contribution of the prefrontal cortex is scarce or indirect. At a minimum, detailed descriptions of conscious patients after extensive bilateral frontal resections demonstrate that an entirely intact prefrontal cortex is not necessary for consciousness. It remains possible that some prefrontal regions may contribute specific conscious contents, such as feelings of reflection, valuation, and affect (Koch et al., 2016a). In the future, withinstate paradigms applied to sleep dreaming (Siclari et al., 2017) and daydreaming (Perogamvros et al., 2017) will be critical to dissociate content-specific NCC from task-related cognitive processes (Koch et al., 2016b).

\section{Measuring brain complexity to detect (and promote) the recovery of consciousness.}

Detecting the presence of consciousness in clinical practice relies ultimately on a behavioral input-output paradigm: a neurologist typically probes the patient with sensory stimuli of different modalities or verbal commands and observes his motor responses (Giacino et al., 2004). If the patient reliably produces outputs that are specific for the different inputs, he is considered conscious. The earlier sections of this review already pointed out that this approach can be problematic: unresponsiveness can be paired with consciousness. However, thanks to recent conceptual and technical advances, a similar input-output paradigm can now be applied even to patients who are fully paralyzed and cannot engage in motor behavior (Owen et al., 2006; Cruse et al., 2011; Naci et al., 2014). In this case, subjects are still presented with sensory stimuli or verbal instructions (e.g., "imagine playing tennis"), but the blockage of motor output is bypassed by directly reading-out neuronal responses with fMRI or EEG. These neuroimaging paradigms can be easily interpreted in case of positive results: unresponsive subjects who willfully produce neuronal activations that are consistent and specific for the given input are considered conscious. However, many brain-injured patients may recover consciousness, yet fail to produce the appropriate neuronal responses (Monti et al., 2010; Bardin et al., 2011).

One potential reason for this false-negative result is that consciousness may be present not only independently of executive/ motor functions but also in the absence of sensory processing. For example, during dreaming, complex, temporally unfolding episodes can be as intense and vivid as waking experiences, yet sensory stimuli are typically ignored and rarely incorporated into the experience (Koulack, 1969; Nir and Tononi, 2010). Consciousness may completely disconnect from the external environment also during some forms of anesthesia, such as ketamine, which induces a dreamlike, hallucinatory state associated with sensory disconnection and complete unresponsiveness (Hejja and Galloon, 1975). Similar disconnections may occur in pathological conditions, whereby patients may be conscious but fail to produce the right neuronal responses to peripheral stimuli just because their sensory pathways and cortices are damaged or functionally disabled. Indeed, intensive care medicine is artificially producing, as a byproduct of saving many lives, brains that may remain isolated, split, or fragmented (Schiff et al., 1999). In the extreme case, large cortical islands, or an archipelago of islands, may survive totally dissociated from the world outside (Gosseries et al., 2014). Can these islands sustain consciousness? Does it feel like anything to be a big chunk of isolated human cortex? For now, we cannot answer this question. What we know is that in such cases assessing consciousness based on sensory inputs and motor/neuronal outputs would be ineffective.

To address this problem, it would be useful to develop complementary metrics to probe directly the internal brain capacity for consciousness (i.e., the full NCC as defined in Koch et al., 2016b) independently of the integrity of sensory processing and executive functions. With this in mind, a novel metric, the Perturbational Complexity Index (PCI), was recently introduced (Casali et al., 2013). PCI is directly inspired by the Integrated information theory of Consciousness (Tononi et al., 2016) and by its fundamental phenomenological axiom: each conscious experience is both differentiated (i.e., it has many specific features that distinguish it from a large repertoire of other experiences) and integrated (i.e., it cannot be divided into independent components). Thus, PCI gauges directly the amount of information (differentiation) that can be generated through large-scale causal interactions (integration) within the thalamocortical system. Operationally, the index quantifies the complexity (algorithmic compressibility) of the EEG response to a direct cortical perturbation with TMS.

Put simply, PCI involves perturbing directly the thalamocortical system and characterizing the "echo" it produces, an approach very similar to what we would do with any unknown object; we knock on it with our knuckles and deduce what it might contain based on the sound it makes. Per theoretical postulates, a conscious brain should "sound" very different from an unconscious one. When consciousness is lost, the TMS-EEG "echo" will either be local because neurons are unable to engage in reciprocal causal interactions (low integration), or it will be global but stereotypical, because all elements engage in the same pattern (low differentiation). The EEG echo will be both global and differentiated (i.e., complex) only if many elements interact through specific mechanisms (integrated information).

Albeit macroscopic and coarse, the PCI measurement provided maximum (100\%) accuracy in detecting consciousness in a large $(n=150)$ benchmark population of subjects who could confirm the presence or absence of conscious experience through immediate or delayed reports. Brain complexity was lower in all unresponsive subjects who did not report any conscious experience upon awakening from NREM sleep or midazolam, xenon, and propofol anesthesia, and was invariably higher in conditions in which consciousness was present, including awake controls and subjects who were disconnected and unresponsive during rapid eye movement (REM) sleep and ketamine anesthesia but retrospectively reported having had vivid conscious experiences upon awakening. Once calibrated on the gold standard of subjective reports, PCI measurements performed at the bedside of brain-injured noncommunicating subjects offered unprecedented sensitivity (94\%) in detecting minimal consciousness in patients and allowed identifying a significant percentage $(\sim 20 \%)$ of vegetative state/unresponsive wakefulness syndrome cases with high brain complexity. In these behaviorally unresponsive patients, PCI values overlapped with the distribution of the benchmark conscious condition, suggesting the presence of disconnected consciousness, which eventually resulted in a higher rate of recovery (Casarotto et al., 2016).

Measuring complexity and studying its mechanisms in the brain may also offer valuable insights on the neuronal bases of loss and recovery of consciousness. TMS is a strong, coarse- 
grained perturbation that activates many diverging cortical and corticosubcortical connections; therefore, PCI is a global measure that cannot resolve whether there are preferential hubs of complexity within the brain (e.g., in the parietal or in the frontal lobe). Ongoing studies using localized, intracortical single-pulse electrical stimuli and mesoscale (local field potential) recordings may provide deeper insight. For example, a recent intracranial human study (Pigorini et al., 2015) identified a simple mechanism by which the emergence of sustained interaction among cortical areas may be impaired during dreamless sleep: upon receiving an input, cortical neurons tend to respond briefly, then hush and "forget." This behavior, a potential killer for brain complexity, is due to a basic dynamic, also known as cortical bistability, by which individual neurons tend to fall into a silent hyperpolarized state (down state) after an initial activation (up state) (Compte et al., 2003; Sanchez-Vives et al., 2017). Down states, which are mainly engendered by activity-dependent potassium $\left(\mathrm{K}^{+}\right)$currents during physiological NREM sleep (Timofeev et al., 2001), may be generally relevant for consciousness and its disorders for at least three reasons. First, they can also occur in pathological conditions due to alterations of the inhibition/excitation balance (Murase et al., 2004) or as a consequence of white matter injury (Timofeev et al., 2000). Second, they can be investigated from the intracellular level in animal models (Steriade et al., 1993) to the whole network level in humans (Cash et al., 2009). Third, they can impair network interactions globally (Lewis et al., 2012; Pigorini et al., 2015; Olcese et al., 2016), but they are in principle reversible.

Notably, a recent microscale study using electrical stimulation and recordings in isolated cortical slices (an extreme case of cortical island) showed that complex causal interactions, as assessed by an adapted version of PCI, can be restored by pharmacological manipulations that reduce neuronal bistability (D'Andola et al., 2017). Can some of these concepts be translated to the bedside of comatose patients? Some patients with vegetative state/unresponsive wakefulness syndrome spontaneously flip from a lowcomplexity condition to a conscious high-complexity state for no apparent reason (Rosanova et al., 2012). Will we be able to understand and promote this process? In the years to come, it will be crucial to further elucidate the relationships between singleneuron dynamics, overall network complexity, and consciousness through extensive experiments across scales, species, and models.

\section{The conscious rodent brain: ensemble activity and long-range correlation patterns}

Animal models provide a unique window to probe the neuronlevel mechanisms of many cognitive processes, including consciousness. Rodents, in particular, offer an unprecedented range of tools to access all circuital elements of the brain, and share many features with the human brain. However, when addressing the question of consciousness in rodents or other animals, it is crucial to ask whether these animals can be conscious at all. It is a valid question regardless of species, applying to nonhuman primates as well as rodents. Although one may adopt an agnostic stance on the topic and just call for further research (Gutfreund, 2017), there is an increasing need to come up with a neuroscientific account of animal consciousness, not necessarily providing definitive answers but rather a "best estimate" facilitating rational decisions on issues of great societal relevance, such as ritual slaughter and pain mitigation in animal health care.

The question of rodent consciousness can be split into two components: (1) do rodent brains have conscious states as op- posed to unconscious states (e.g., during dreamless sleep or anesthesia)? (2) What are the contents of consciousness as experienced by rodents? The first question is less difficult to address than the second, as is also the case for nonhuman primates and humans: conscious contents refer to subjective and qualitative aspects of our experiences, which are notoriously hard to get at due to their essentially private nature. In contrast, there are several arguments in favor of rodents having at least a basic capacity to sustain conscious states: (1) the fact that electrophysiological markers indicative of conscious states in humans and primates are also found in rodent brains (e.g., markers for wakefulness and REM sleep, such as desynchronized EEG, as opposed to slow waves in NREM sleep); (2) the strong anatomical homologies between the systems in rodent and human brains deemed important for conscious states (mainly, thalamocortical systems); and (3) the presence of behavioral indicators of conscious states, overlapping in use and applicability between humans and rodents. Such indicators do not only include sleep-wake cycles and markers of wakefulness, such as behavioral reactivity to sensory stimuli and orienting responses, but also the ability to generate nonhabitual (i.e., goal-directed) behaviors (Weiskrantz, 1995; Pennartz, 2015) and distinctive behavioral responses when stimuli are perceived or not (Carandini and Churchland, 2013). A fourth argument is based on recently developed measures of consciousness (Massimini et al., 2005; Ferrarelli et al., 2010; Casali et al., 2013). As in humans and primates, wakeful states in rodents are marked by a higher degree of complexity (Hudetz et al., 2015, 2016) and long-range functional connectivity than during deep, NREM sleep or anesthesia (Olcese et al., 2016). This fourth argument goes beyond "physiological hallmarks" because it is based on inferred functional properties of conscious systems, such as the ability to integrate complex information (Tononi and Edelman, 1998), to generate interactions and joint coding between sensory modalities and memory (Pennartz, 2009), and to represent a near-instantaneous "world model" efficiently and usefully (Pennartz, 2015). While many questions also regarding this argument remain open in rodents, our best, evidence-based guess is that rodent brains are indeed capable of sustaining conscious states, regardless of the precise complexity and richness of represented contents compared with primates. Here we will review recent findings related to this fourth argument, and discuss how they expand our understanding of NCCs in the rodent brain.

The ability to integrate complex information and generate interactions sustaining world representations eventually resides in the brain's information-coding elements: neurons. Because most previous comparisons between conscious, sleep, and anesthetized states in humans have used recording techniques with macroscopic and mesoscopic resolution (Massimini et al., 2005; Ferrarelli et al., 2010; Park and Friston, 2013; but see Lewis et al., 2012) (EEG, local field potential, or fMRI), it has been difficult to determine how the loss of global functional connectivity (e.g., during transitions from wakefulness to NREM sleep) is associated with cell-level changes in correlation patterns. The few studies on the topic are somewhat inconsistent and report either no change in functional connectivity between conscious and unconscious states (Zhang et al., 2014) or a dramatic loss of communication (Makino and Komiyama, 2015; Ishizawa et al., 2016). We investigated this using multiarea tetrode recordings in sensory neocortex and hippocampus of rats undergoing transitions from wakefulness to NREM sleep (for methods, see Bos et al., 2017). We computed conditional mutual information (cMI) to quantify functional connectivity between spike train patterns across all cell pairs, as this measure includes nonlinear correlations that would 
A

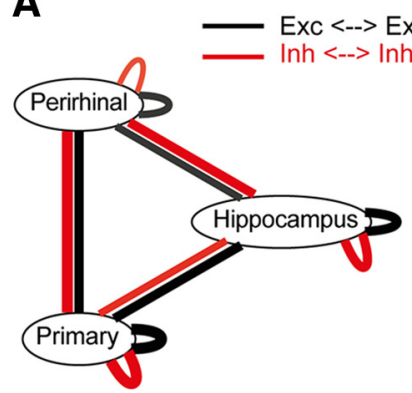

Wakefulness

B

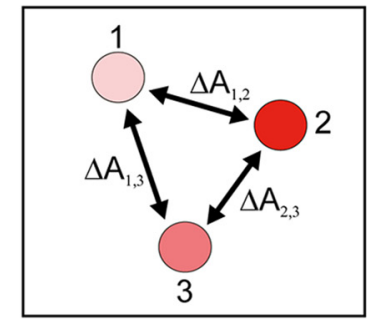

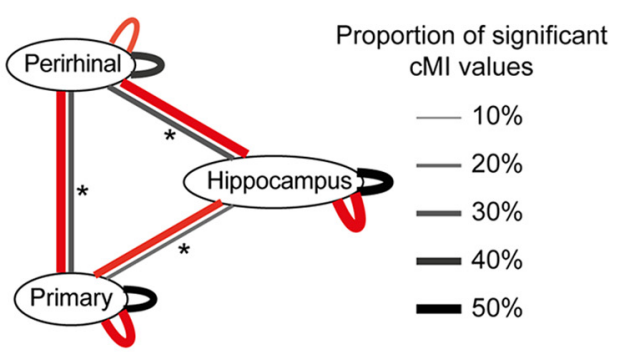

Non-REM
D

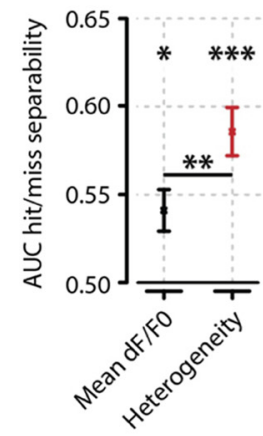

C

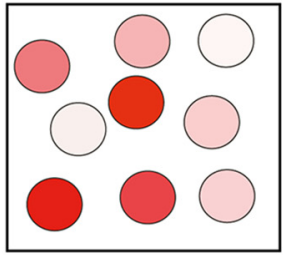

High

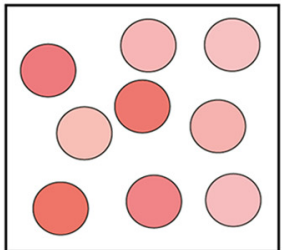

Low Heterogeneity

Figure 4. A, Summary of main findings on spike-based functional connectivity in rats (Olcese et al., 2016). Coupling was measured as pairwise cMl between single neurons. During wakefulness, cMl between neurons located in the same or different areas is largely balanced (left) for both excitatory and inhibitory neurons (black and red lines, respectively). In NREM sleep, interareal (but not intra-area) coupling between excitatory neurons is significantly reduced. This did not apply to intra-area cMl and interareal cMI (between interneurons). Line thickness indicates the proportion of neuronal pairs for which cMl was significantly $>0$. Asterisks indicate which connections showed a significant change between wakefulness and NREM sleep (the only significant differences found pertained to interareal coupling between excitatory neurons). Thus, during NREM sleep, neural computations may continue in local "islands of activity," whereas global integration capabilities are reduced. B, Calculation of heterogeneity across a neuronal population (compare Montijn et al., 2015). A measure of a neuronal activity change (A, e.g., the relative fluorescence response of a neuron in 2-photon imaging, $\mathrm{dF} / \mathrm{F}_{0}$ ) is computed across all neurons. Next, the responses are $z$-scored per neuron across all trials and all trial types (e.g., in a given session, visual stimuli are presented at 6 different contrasts; each contrast is presented 20 times; 120 trials in total). Per trial, the absolute difference in $z$-scored activity is then calculated across all pairs of neurons (e.g., $\Delta \mathrm{A}_{1,2}$ is the difference between the responses of neurons 1 and 2). The population heterogeneity in a given trial is the mean of activity differences across all pairs. $\boldsymbol{C}$, Examples of high (left) versus low heterogeneity (right) in a neuronal population, where response strength is indicated by color saturation. $\boldsymbol{D}$, In a visual stimulus detection task performed by mice that were subjected to 2-photon imaging of V1 neuronal populations, heterogeneity was better capable of separating hit (detection) and miss (nondetection) trials than the mean fluorescence response (area under the curve resulting from receiver-operating characteristic analysis). Both measures predicted response behavior above chance: mean response, ${ }^{*} p<0.05$; heterogeneity, ${ }^{* * *} p<0.001$; area under the curve $=0.5$, chance level. Behavior was predicted better by heterogeneity than mean response $\left({ }^{* *} p<0.01\right)$. Values are mean \pm SEM across animals. Data from Montijn et al. (2015).

escape detection by linear methods (Steuer et al., 2002; MacKay, 2003). Although the results showed area-specific changes in correlation patterns, they confirmed that global functional connectivity drops from wakefulness to NREM sleep (Olcese et al., 2016). This effect was due to a selective loss of interareal interactions between excitatory neurons but not interneurons, whereas intra-areal connectivity was largely preserved for both neuronal types (Fig. 4A). Thus, the drop in global connectivity during NREM sleep is not paralleled by a similar drop in intra-areal connectivity, allowing local computations in relative "islands of activity" to continue. Because cMI does not indicate the direction of information flow between neurons, we also computed the transfer entropy between spiking neurons, and found that this measure allows to distinguish several regimes for directed communication in the brain, depending on the time scale of neural interaction, the anatomical distance between neurons, and, intriguingly, the presence of a neural correlate to the behavioral task performed by the animal before NREM sleep (U.O. et al., unpublished observations).

In addition to spike-based markers distinguishing different brain states, we set out to study differences in ensemble behavior within the awake, conscious state, when animals performed a visual detection task. While correlates of conscious perception have been recently described at the level of membrane potential dynamics and spiking activity (Pinto et al., 2013; Sachidhanandam et al., 2013; Manita et al., 2015; Takahashi et al., 2016), especially involving recurrent activity between cortical areas, it is still poorly understood how perception is reflected in population dynamics. Using a range of visual contrasts, mice were trained to respond to presentations of moving gratings by performing licking actions (however, note that this go/no go paradigm does not exhaustively test for consciousness (Koch, 2004; Montijn et al., 2015; Pennartz, 2015). Ensemble activity in layer 2-3 of mouse $\mathrm{V} 1$ was recorded by 2 -photon $\mathrm{Ca}^{2+}$ imaging, and we asked which of two measures would more accurately correspond to hit versus miss trials: the mean somatic $\mathrm{Ca}^{2+}$ response or the population heterogeneity (for explanation, see Fig. $4 B, C$ ). We found that heterogeneity allowed a significantly better separation between hit and miss trials than the mean response (Montijn et al., 2015) (Figure 4D). Moreover, applying heterogeneity (but not mean $\mathrm{dF} / \mathrm{F}_{0}$ ) to the baseline (prestimulus) period, it proved feasible to predict the type of detection response (fast hit response vs miss or slow response). Thus, heterogeneity of single-cell responses within larger ensembles may indicate a neural correlate of detection and/or perception along with arousal and attention (Pinto et al., 2013). We suggest that a state of high heterogeneity arises in association with EEG desynchronization, and is conducive to having a high degree of differentiated, stimulus-specific coding in 
a neural network (Pennartz, 2009; Goltstein et al., 2015; Tononi et al., 2016; compare Renart et al., 2010). In line with this, the presence and orientation of the stimulus were better decodable from the population when the animal made a correct detection response and heterogeneity was high. Strong heterogeneity in sensory cortical cell populations may thus correlate with better representational performance. However, this position does not exhaust the repertoire of potential neural correlates: when analyzing assembly activity as manifested by multineuron activity sequences, we found that visual detection (hit trials) was also paired with a higher consistency in the timing of single-cell activity within the sequence than nondetection (miss trials) (Montijn et al., 2015).

Although rodent behavioral paradigms need to be developed further to yield more specific markers of consciousness, we may conclude that ensemble studies are beginning to reveal population and network phenomena relevant for understanding not only what conscious states consist of (i.e., the cell-level nature of NCCs), but also why such states are conducive for optimal coding of the stimuli and complex scenes of which we can become conscious.

\section{Conclusions and perspectives}

In conclusion, consciousness, once regarded as a purely philosophical topic, the "mind-body problem", has become an active research field in neuroscience. Neuroscientific consciousness research, boosted by novel methods and theoretical advances, has become increasingly accepted and mature, and is now beginning to yield remarkable scientific and clinical progress.

As is often the case within a developing branch of science, concepts and mechanisms that were previously often blended and confused are now being teased apart and more clearly defined. "Content-specific" and "full" NCCs are becoming increasingly well defined. Improved strategies allow conscious experience to be distinguished from related enabling and executive functions, for example, through employment of refined behavioral/no-report paradigms, local inactivation and lesions, and noninvasive brain stimulation. A closely related, critical reevaluation of the prefrontal cortex' role in consciousness suggests that, although important for behavioral reporting and other executive functions, it is not crucial for conscious experiences per se. Instead, converging evidence points to a posterior "hot zone" for consciousness including parietal, temporal, and occipital areas.

Methods for objective assessment of consciousness are crucial, both experimentally and clinically. The PCI is a highly promising metric for detecting consciousness, inspired by the Integrated information theory. Without requiring any sensory input or behavioral report (i.e., executive functions), PCI seems to be a reliable indicator of the human brain's capacity for consciousness, being related to the amount of information that can be generated through causal brain interactions. PCI has recently proved highly accurate in a large benchmark population of conscious or unconscious subjects.

This progress also offers insights into neuronal bases of loss and recovery of consciousness, and how these may be manipulated. Thus, converging evidence from animals and humans suggest that neuronal "bistability," a dynamic property of cortical circuits, can cause unconsciousness by impairing brain complexity. Recently, pharmacological suppression of bistability was shown to restore the complex causal interactions required for consciousness. Rodent models are being developed to allow dissection of molecular, cellular, and circuit mechanisms of consciousness. Ensemble recordings begin to reveal how, in addition to complexity measures, heterogeneity and spike-based measures of functional connectivity can be used to differentiate conscious and unconscious states, and why conscious states promote optimal coding. Population coding studies promise to enable researchers to study consciousness in terms of brain-generated representations, thus supplementing global assessments of integrated information.

Rather than trying to solve all major theoretical problems first, we advocate an interleaved practical and theoretical approach. Experiments across scales, species, and models, spanning from ion channels, neurons, and microcircuits to whole-brain simulations, from unit and ensemble recordings in animals to the patient's bedside, will be crucial for bridging the gaps between single-neuron dynamics, overall network complexity, and conscious experience. This is a daunting task and the stakes are high, but the recent progress is promising.

\section{References}

Ajina S, Pestilli F, Rokem A, Kennard C, Bridge H (2015) Human blindsight is mediated by an intact geniculo-extrastriate pathway. Elife 4:e08935. Medline

Alkire MT, Hudetz AG, Tononi G (2008) Consciousness and anesthesia. Science 322:876-880. CrossRef Medline

Aru J, Axmacher N, Do Lam AT, Fell J, Elger CE, Singer W, Melloni L (2012a) Local category-specific gamma band responses in the visual cortex do not reflect conscious perception. J Neurosci 32:14909-14914. CrossRef Medline

Aru J, Bachmann T, Singer W, Melloni L (2012b) Distilling the neural correlates of consciousness. Neurosci Biobehav Rev 36:737-746. CrossRef Medline

Bardin JC, Fins JJ, Katz DI, Hersh J, Heier LA, Tabelow K, Dyke JP, Ballon DJ, Schiff ND, Voss HU (2011) Dissociations between behavioural and functional magnetic resonance imaging-based evaluations of cognitive function after brain injury. Brain 134:769-782. CrossRef Medline

Barton JJ (2011) Disorders of higher visual processing. Handb Clin Neurol 102:223-261. CrossRef Medline

Bayne T, Hohwy J, Owen AM (2016) Are there levels of consciousness? Trends Cogn Sci 20:405-413. CrossRef Medline

Beauchamp MS, Sun P, Baum SH, Tolias AS, Yoshor D (2012) Electrocorticography links human temporoparietal junction to visual perception. Nat Neurosci 15:957-959. CrossRef Medline

Blake R, Logothetis N (2002) Visual competition. Nat Rev Neurosci 3:1321. CrossRef Medline

Boly M, Seth AK, Wilke M, Ingmundson P, Baars B, Laureys S, Edelman DB, Tsuchiya N (2013) Consciousness in humans and non-human animals: recent advances and future directions. Front Psychol 4:625. CrossRef Medline

Boly M, Massimini M, Tsuchiya N, Postle BR, Koch C, Tononi G (2017) Are the neural correlates of consciousness in the front or in the back of the cerebral cortex? Clinical and neuroimaging evidence. J Neurosci 37:96039613. CrossRef Medline

Bor D, Seth AK (2012) Consciousness and the prefrontal parietal network: insights from attention, working memory, and chunking. Front Psychol 3:63. CrossRef Medline

Bos JJ, Vinck M, van Mourik-Donga LA, Jackson JC, Witter MP, Pennartz CM (2017) Perirhinal firing patterns are sustained across large spatial segments of the task environment. Nat Commun 8:15602. CrossRef Medline

Brascamp J, Sterzer P, Blake R, Knapen T (2018) Multistable perception and the role of frontoparietal cortex in perceptual inference. Annu Rev Psychol. Advance online publication. Retrieved Aug. 30, 2017. doi: 10.1146/ annurev-psych-010417-085944. CrossRef Medline

Brickner RM (1952) Brain of patient A after bilateral frontal lobectomy: status of frontal-lobe problem. AMA Arch Neurol Psychiatry 68:293-313. CrossRef Medline

Carandini M, Churchland AK (2013) Probing perceptual decisions in rodents. Nat Neurosci 16:824-831. CrossRef Medline

Casali AG, Gosseries O, Rosanova M, Boly M, Sarasso S, Casali KR, Casarotto S, Bruno MA, Laureys S, Tononi G, Massimini M (2013) A theoretically 
based index of consciousness independent of sensory processing and behavior. Sci Transl Med 5:198ra105. CrossRef Medline

Casarotto S, Comanducci A, Rosanova M, Sarasso S, Fecchio M, Napolitani M, Pigorini A, G Casali A, Trimarchi PD, Boly M, Gosseries O, Bodart O, Curto F, Landi C, Mariotti M, Devalle G, Laureys S, Tononi G, Massimini M (2016) Stratification of unresponsive patients by an independently validated index of brain complexity. Ann Neurol 80:718-729. CrossRef Medline

Cash SS, Halgren E, Dehghani N, Rossetti AO, Thesen T, Wang C, Devinsky O, Kuzniecky R, Doyle W, Madsen JR, Bromfield E, Eross L, Halász P, Karmos G, Csercsa R, Wittner L, Ulbert I (2009) The human K-complex represents an isolated cortical down-state. Science 324:1084-1087. CrossRef Medline

Christopoulos VN, Bonaiuto J, Kagan I, Andersen RA (2015) Inactivation of parietal reach region affects reaching but not saccade choices in internally guided decisions. J Neurosci 35:11719-11728. CrossRef Medline

Compte A, Sanchez-Vives MV, McCormick DA, Wang XJ (2003) Cellular and network mechanisms of slow oscillatory activity $(<1 \mathrm{~Hz})$ and wave propagations in a cortical network model. J Neurophysiol 89:2707-2725. CrossRef Medline

Cowey A, Stoerig P (1995) Blindsight in monkeys. Nature 373:247-249. CrossRef Medline

Crick F (2004) Foreword. In: The quest for consciousness: a neurobiological approach (Koch C, ed), p xiii. Englewood, CO: Roberts.

Crick F, Koch C (1998) Consciousness and neuroscience. Cereb Cortex 8:97-107. CrossRef Medline

Cruse D, Chennu S, Chatelle C, Bekinschtein TA, Fernández-Espejo D, Pickard JD, Laureys S, Owen AM (2011) Bedside detection of awareness in the vegetative state: a cohort study. Lancet 378:2088-2094. CrossRef Medline

D’Andola M, Rebollo B, Casali AG, Weinert JF, Pigorini A, Villa R, Massimini M, Sanchez-Vives MV (2017) Bistability, causality, and complexity in cortical networks: an in vitro perturbational study. Cereb Cortex. Advance online publication. Retrieved Aug. 30, 2017. doi: 10.1093/cercor/ bhx122. CrossRef Medline

de Graaf TA, Sack AT (2014) Using brain stimulation to disentangle neural correlates of conscious vision. Front Psychol 5:1019. CrossRef Medline

de Graaf TA, Hsieh PJ, Sack AT (2012) The 'correlates' in neural correlates of consciousness. Neurosci Biobehav Rev 36:191-197. CrossRef Medline

Dehaene S, Changeux JP (2004) Neural mechanisms for access to consciousness. In: The cognitive neurosciences, third edition (Gazzaniga MS, ed), p 1145. Cambridge, MA: The MIT Press.

Dehaene S, Changeux JP (2011) Experimental and theoretical approaches to conscious processing. Neuron 70:200-227. CrossRef Medline

Del Cul A, Dehaene S, Reyes P, Bravo E, Slachevsky A (2009) Causal role of prefrontal cortex in the threshold for access to consciousness. Brain 132: 2531-2540. CrossRef Medline

Demertzi A, Antonopoulos G, Heine L, Voss HU, Crone JS, de Los Angeles C, Bahri MA, Di Perri C, Vanhaudenhuyse A, Charland-Verville V, Kronbichler M, Trinka E, Phillips C, Gomez F, Tshibanda L, Soddu A, Schiff ND, Whitfield-Gabrieli S, Laureys S (2015) Intrinsic functional connectivity differentiates minimally conscious from unresponsive patients. Brain 138:2619-2631. CrossRef Medline

Dominguez-Vargas AU, Schneider L, Wilke M, Kagan I (2017) Electrical microstimulation of the pulvinar biases saccade choices and reaction times in a time-dependent manner. J Neurosci 37:2234-2257. CrossRef Medline

Driver J, Mattingley JB (1998) Parietal neglect and visual awareness. Nat Neurosci 1:17-22. CrossRef Medline

Emrich SM, Riggall AC, Larocque JJ, Postle BR (2013) Distributed patterns of activity in sensory cortex reflect the precision of multiple items maintained in visual short-term memory. J Neurosci 33:6516-6523. CrossRef Medline

Farah M (2004) Visual agnosia. Cambridge, MA: Massachusetts Institute of Technology.

Ferrarelli F, Massimini M, Sarasso S, Casali A, Riedner BA, Angelini G, Tononi G, Pearce RA (2010) Breakdown in cortical effective connectivity during midazolam-induced loss of consciousness. Proc Natl Acad Sci U S A 107:2681-2686. CrossRef Medline

Frässle S, Sommer J, Jansen A, Naber M, Einhäuser W (2014) Binocular rivalry: frontal activity relates to introspection and action but not to perception. J Neurosci 34:1738-1747. CrossRef Medline
Gaskell AL, Hight DF, Winders J, Tran G, Defresne A, Bonhomme V, Raz A, Sleigh JW, Sanders RD (2017) Frontal alpha- $\delta$ EEG does not preclude volitional response during anaesthesia: prospective cohort study of the isolated forearm technique. Br J Anaesthesia, in press.

Giacino JT, Kalmar K, Whyte J (2004) The JFK Coma Recovery Scale-Revised: measurement characteristics and diagnostic utility. Arch Phys Med Rehabil 85:2020-2029. CrossRef Medline

Goltstein PM, Montijn JS, Pennartz CM (2015) Effects of isoflurane anesthesia on ensemble patterns of $\mathrm{Ca}^{2+}$ activity in mouse $\mathrm{vl}$ : reduced direction selectivity independent of increased correlations in cellular activity. PLoS One 10:e0118277. CrossRef Medline

Goodale MA, Milner AD, Jakobson LS, Carey DP (1991) A neurological dissociation between perceiving objects and grasping them. Nature 349: 154-156. CrossRef Medline

Gosseries O, Di H, Laureys S, Boly M (2014) Measuring consciousness in severely damaged brains. Annu Rev Neurosci 37:457-478. CrossRef Medline

Gutfreund Y (2017) The neuroethological paradox of animal consciousness. Trends Neurosci 40:196-199. CrossRef Medline

Harvey M, Rossit S (2012) Visuospatial neglect in action. Neuropsychologia 50:1018-1028. CrossRef Medline

Haynes JD (2009) Decoding visual consciousness from human brain signals. Trends Cogn Sci 13:194-202. CrossRef Medline

Hejja P, Galloon S (1975) A consideration of ketamine dreams. Can Anaesth Soc J 22:100-105. CrossRef Medline

Hobson JA, Hong CC, Friston KJ (2014) Virtual reality and consciousness inference in dreaming. Front Psychol 5:1133. CrossRef Medline

Horikawa T, Tamaki M, Miyawaki Y, Kamitani Y (2013) Neural decoding of visual imagery during sleep. Science 340:639-642. CrossRef Medline

Hudetz AG, Vizuete JA, Pillay S, Ropella KM (2015) Critical changes in cortical neuronal interactions in anesthetized and awake rats. Anesthesiology 123:171-180. CrossRef Medline

Hudetz AG, Liu X, Pillay S, Boly M, Tononi G (2016) Propofol anesthesia reduces Lempel-Ziv complexity of spontaneous brain activity in rats. Neurosci Lett 628:132-135. CrossRef Medline

Hupé JM, Lamirel C, Lorenceau J (2009) Pupil dynamics during bistable motion perception. J Vis 9:10. CrossRef Medline

Hwang EJ, Hauschild M, Wilke M, Andersen RA (2012) Inactivation of the parietal reach region causes optic ataxia, impairing reaches but not saccades. Neuron 76:1021-1029. CrossRef Medline

Hwang EJ, Hauschild M, Wilke M, Andersen RA (2014) Spatial and temporal eye-hand coordination relies on the parietal reach region. J Neurosci 34:12884-12892. CrossRef Medline

Ishizawa Y, Ahmed OJ, Patel SR, Gale JT, Sierra-Mercado D, Brown EN, Eskandar EN (2016) Dynamics of propofol-induced loss of consciousness across primate neocortex. J Neurosci 36:7718-7726. CrossRef Medline

Kampfl A, Schmutzhard E, Franz G, Pfausler B, Haring HP, Ulmer H, Felber S, Golaszewski S, Aichner F (1998) Prediction of recovery from posttraumatic vegetative state with cerebral magnetic-resonance imaging. Lancet 351:1763-1767. CrossRef Medline

Karnath HO (2001) New insights into the functions of the superior temporal cortex. Nat Rev Neurosci 2:568-576. CrossRef Medline

Karnath HO, Himmelbach M, Rorden C (2002) The subcortical anatomy of human spatial neglect: putamen, caudate nucleus and pulvinar. Brain 125:350-360. CrossRef Medline

Katz LN, Yates JL, Pillow JW, Huk AC (2016) Dissociated functional significance of decision-related activity in the primate dorsal stream. Nature 535:285-288. CrossRef Medline

Kerkhoff G (2001) Spatial hemineglect in humans. Prog Neurobiol 63:1-27. CrossRef Medline

Kim CY, Blake R (2005) Psychophysical magic: rendering the visible 'invisible.' Trends Cogn Sci 9:381-388. CrossRef Medline

King JR, Sitt JD, Faugeras F, Rohaut B, El Karoui I, Cohen L, Naccache L, Dehaene S (2013) Information sharing in the brain indexes consciousness in noncommunicative patients. Curr Biol 23:1914-1919. CrossRef Medline

Kloosterman NA, Meindertsma T, van Loon AM, Lamme VA, Bonneh YS, Donner TH (2015) Pupil size tracks perceptual content and surprise. Eur J Neurosci 41:1068-1078. CrossRef Medline

Knapen T, Brascamp J, Pearson J, van Ee R, Blake R (2011) The role of frontal and parietal brain areas in bistable perception. J Neurosci 31: 10293-10301. CrossRef Medline 
Koch C (2004) The quest for consciousness. Englewood, CO: Roberts.

Koch C, Tsuchiya N (2012) Attention and consciousness: related yet different. Trends Cogn Sci 16:103-105. CrossRef Medline

Koch C, Massimini M, Boly M, Tononi G (2016a) Posterior and anterior cortex: where is the difference that makes the difference? Nat Rev Neurosci 17:666. CrossRef Medline

Koch C, Massimini M, Boly M, Tononi G (2016b) Neural correlates of consciousness: progress and problems. Nat Rev Neurosci 17:307-321. CrossRef Medline

Komura Y, Nikkuni A, Hirashima N, Uetake T, Miyamoto A (2013) Responses of pulvinar neurons reflect a subject's confidence in visual categorization. Nat Neurosci 16:749-755. CrossRef Medline

Koulack D (1969) Effects of somatosensory stimulation on dream content. Arch Gen Psychiatry 20:718-725. CrossRef Medline

Laeng B, Endestad T (2012) Bright illusions reduce the eye's pupil. Proc Natl Acad Sci U S A 109:2162-2167. CrossRef Medline

Laeng B, Sirois S, Gredebäck G (2012) Pupillometry: a window to the preconscious? Perspect Psychol Sci 7:18-27. CrossRef Medline

Laureys S, Schiff ND (2012) Coma and consciousness: paradigms (re) framed by neuroimaging. Neuroimage 61:478-491. CrossRef Medline

Leopold DA, Logothetis NK (1999) Multistable phenomena: changing views in perception. Trends Cogn Sci 3:254-264. CrossRef Medline

Leopold DA, Logothetis NK (2003) Spatial patterns of spontaneous local field activity in the monkey visual cortex. Rev Neurosci 14:195-205. Medline

Leopold DA, Plettenberg HK, Logothetis NK (2002) Visual processing in the ketamine-anesthetized monkey: optokinetic and blood oxygenation level-dependent responses. Exp Brain Res 143:359-372. CrossRef Medline

Leopold DA, Maier A, Logothetis NK (2003) Measuring subjective visual perception in the nonhuman primate. J Conscious Stud 10:115-130.

Lewis LD, Weiner VS, Mukamel EA, Donoghue JA, Eskandar EN, Madsen JR, Anderson WS, Hochberg LR, Cash SS, Brown EN, Purdon PL (2012) Rapid fragmentation of neuronal networks at the onset of propofolinduced unconsciousness. Proc Natl Acad Sci U S A 109:E3377-E3386. CrossRef Medline

MacKay DJC (2003) Information theory, inference and learning algorithms. Cambridge, UK: Cambridge UP.

Maier A, Wilke M, Aura C, Zhu C, Ye FQ, Leopold DA (2008) Divergence of fMRI and neural signals in V1 during perceptual suppression in the awake monkey. Nat Neurosci 11:1193-1200. CrossRef Medline

Makino H, Komiyama T (2015) Learning enhances the relative impact of top-down processing in the visual cortex. Nat Neurosci 18:1116-1122. CrossRef Medline

Manita S, Suzuki T, Homma C, Matsumoto T, Odagawa M, Yamada K, Ota K, Matsubara C, Inutsuka A, Sato M, Ohkura M, Yamanaka A, Yanagawa Y, Nakai J, Hayashi Y, Larkum ME, Murayama M (2015) A top-down cortical circuit for accurate sensory perception. Neuron 86:1304-1316. CrossRef Medline

Massimini M, Ferrarelli F, Huber R, Esser SK, Singh H, Tononi G (2005) Breakdown of cortical effective connectivity during sleep. Science 309: 2228-2232. CrossRef Medline

Mataró M, Jurado MA, García-Sánchez C, Barraquer L, Costa-Jussà FR, Junqué C (2001) Long-term effects of bilateral frontal brain lesion: 60 years after injury with an iron bar. Arch Neurol 58:1139-1142. CrossRef Medline

Miller SM (2007) On the correlation/constitution distinction problem (and other hard problems) in the scientific study of consciousness. Acta Neuropsychiatr 19:159-176. CrossRef Medline

Monti MM, Vanhaudenhuyse A, Coleman MR, Boly M, Pickard JD, Tshibanda L, Owen AM, Laureys S (2010) Willful modulation of brain activity in disorders of consciousness. N Engl J Med 362:579-589. CrossRef Medline

Montijn JS, Goltstein PM, Pennartz CM (2015) Mouse V1 population correlates of visual detection rely on heterogeneity within neuronal response patterns. Elife 4:e10163. CrossRef Medline

Moran JM, Zaki J (2013) Functional neuroimaging and psychology: what have you done for me lately? J Cogn Neurosci 25:834-842. CrossRef Medline

Murase N, Duque J, Mazzocchio R, Cohen LG (2004) Influence of interhemispheric interactions on motor function in chronic stroke. Ann Neurol 55:400-409. CrossRef Medline

Na DL, Adair JC, Williamson DJ, Schwartz RL, Haws B, Heilman KM (1998)
Dissociation of sensory-attentional from motor-intentional neglect. J Neurol Neurosurg Psychiatry 64:331-338. CrossRef Medline

Naci L, Cusack R, Anello M, Owen AM (2014) A common neural code for similar conscious experiences in different individuals. Proc Natl Acad Sci U S A 111:14277-14282. CrossRef Medline

Nir Y, Tononi G (2010) Dreaming and the brain: from phenomenology to neurophysiology. Trends Cogn Sci 14:88-100. CrossRef Medline

Nishimoto S, Vu AT, Naselaris T, Benjamini Y, Yu B, Gallant JL (2011) Reconstructing visual experiences from brain activity evoked by natural movies. Curr Biol 21:1641-1646. CrossRef Medline

Oizumi M, Albantakis L, Tononi G (2014) From the phenomenology to the mechanisms of consciousness: Integrated Information Theory 3.0. PLoS Comput Biol 10:e1003588. CrossRef Medline

Olcese U, Bos JJ, Vinck M, Lankelma JV, van Mourik-Donga LB, Schlumm F, Pennartz CM (2016) Spike-based functional connectivity in cerebral cortex and hippocampus: loss of global connectivity is coupled to preservation of local connectivity during non-REM sleep. J Neurosci 36:76767692. CrossRef Medline

Overgaard M, Fazekas P (2016) Can no-report paradigms extract true correlates of consciousness? Trends Cogn Sci 20:241-242. CrossRef Medline

Owen AM, Coleman MR, Boly M, Davis MH, Laureys S, Pickard JD (2006) Detecting awareness in the vegetative state. Science 313:1402. CrossRef Medline

Panagiotaropoulos TI, Deco G, Kapoor V, Logothetis NK (2012) Neuronal discharges and gamma oscillations explicitly reflect visual consciousness in the lateral prefrontal cortex. Neuron 74:924-935. CrossRef Medline

Park HJ, Friston K (2013) Structural and functional brain networks: from connections to cognition. Science 342:1238411. CrossRef Medline

Penfield W, Jasper HH (1954) Epilepsy and the functional anatomy of the brain. Boston: Little Brown.

Pennartz CM (2009) Identification and integration of sensory modalities: neural basis and relation to consciousness. Conscious Cogn 18:718-739. CrossRef Medline

Pennartz CM (2015) The brain's representational power: on consciousness and the integration of modalities. Cambridge, MA: Massachusetts Institute of Technology.

Perogamvros L, Baird B, Seibold M, Riedner B, Boly M, Tononi G (2017) The phenomenal contents and neural correlates of spontaneous thoughts across wakefulness, NREM sleep and REM sleep. J Cogn Neurosci 29: 1766-1777. CrossRef Medline

Pigorini A, Sarasso S, Proserpio P, Szymanski C, Arnulfo G, Casarotto S, Fecchio M, Rosanova M, Mariotti M, Lo Russo G, Palva JM, Nobili L, Massimini M (2015) Bistability breaks-off deterministic responses to intracortical stimulation during non-REM sleep. Neuroimage 112:105113. CrossRef Medline

Pinto L, Goard MJ, Estandian D, Xu M, Kwan AC, Lee SH, Harrison TC, Feng G, Dan Y (2013) Fast modulation of visual perception by basal forebrain cholinergic neurons. Nat Neurosci 16:1857-1863. CrossRef Medline

Pitts MA, Martínez A, Hillyard SA (2012) Visual processing of contour patterns under conditions of inattentional blindness. J Cogn Neurosci 24: 287-303. CrossRef Medline

Pitts MA, Metzler S, Hillyard SA (2014a) Isolating neural correlates of conscious perception from neural correlates of reporting one's perception. Front Psychol 5:1078. CrossRef Medline

Pitts MA, Padwal J, Fennelly D, Martínez A, Hillyard SA (2014b) Gamma band activity and the P3 reflect post-perceptual processes, not visual awareness. Neuroimage 101:337-350. CrossRef Medline

Poldrack RA (2006) Can cognitive processes be inferred from neuroimaging data? Trends Cogn Sci 10:59-63. CrossRef Medline

Poldrack RA, Yarkoni T (2016) From brain maps to cognitive ontologies: informatics and the search for mental structure. Annu Rev Psychol 67: 587-612. CrossRef Medline

Rangarajan V, Hermes D, Foster BL, Weiner KS, Jacques C, Grill-Spector K, Parvizi J (2014) Electrical stimulation of the left and right human fusiform gyrus causes different effects in conscious face perception. J Neurosci 34:12828-12836. CrossRef Medline

Renart A, de la Rocha J, Bartho P, Hollender L, Parga N, Reyes A, Harris KD (2010) The asynchronous state in cortical circuits. Science 327:587-590. CrossRef Medline

Ro T, Rorden C, Driver J, Rafal R (2001) Ipsilesional biases in saccades but not perception after lesions of the human inferior parietal lobule. J Cogn Neurosci 13:920-929. CrossRef Medline 
Rosanova M, Gosseries O, Casarotto S, Boly M, Casali AG, Bruno MA, Mariotti M, Boveroux P, Tononi G, Laureys S, Massimini M (2012) Recovery of cortical effective connectivity and recovery of consciousness in vegetative patients. Brain 135:1308-1320. CrossRef Medline

Sachidhanandam S, Sreenivasan V, Kyriakatos A, Kremer Y, Petersen CC (2013) Membrane potential correlates of sensory perception in mouse barrel cortex. Nat Neurosci 16:1671-1677. CrossRef Medline

Sahraie A, Trevethan CT, MacLeod MJ, Urquhart J, Weiskrantz L (2013) Pupil response as a predictor of blindsight in hemianopia. Proc Natl Acad Sci U S A 110:18333-18338. CrossRef Medline

Sanchez-Vives MV, Massimini M, Mattia M (2017) Shaping the default activity pattern of the cortical network. Neuron 94:993-1001. CrossRef Medline

Sandberg K, Andersen LM, Overgaard M (2014) Using multivariate decoding to go beyond contrastive analyses in consciousness research. Front Psychol 5:1250. CrossRef Medline

Sanders RD, Tononi G, Laureys S, Sleigh JW (2012) Unresponsiveness $\neq$ unconsciousness. Anesthesiology 116:946-959. CrossRef Medline

Schiff N, Ribary U, Plum F, Llinás R (1999) Words without mind. J Cogn Neurosci 11:650-656. CrossRef Medline

Schmid MC, Mrowka SW, Turchi J, Saunders RC, Wilke M, Peters AJ, Ye FQ, Leopold DA (2010) Blindsight depends on the lateral geniculate nucleus. Nature 466:373-377. CrossRef Medline

Selimbeyoglu A, Parvizi J (2010) Electrical stimulation of the human brain: perceptual and behavioral phenomena reported in the old and new literature. Front Hum Neurosci 4:46. CrossRef Medline

Seth AK, Dienes Z, Cleeremans A, Overgaard M, Pessoa L (2008) Measuring consciousness: relating behavioural and neurophysiological approaches. Trends Cogn Sci 12:314-321. CrossRef Medline

Siclari F, Baird B, Perogamvros L, Bernardi G,LaRocque JJ, Riedner B, Boly M, Postle BR, Tononi G (2017) The neural correlates of dreaming. Nat Neurosci 20:872-878. CrossRef Medline

Stender J, Mortensen KN, Thibaut A, Darkner S, Laureys S, Gjedde A, Kupers $R$ (2016) The minimal energetic requirement of sustained awareness after brain injury. Curr Biol 26:1494-1499. CrossRef Medline

Steriade M, Nuñez A, Amzica F (1993) A novel slow ( $<1 \mathrm{~Hz}$ ) oscillation of neocortical neurons in vivo: depolarizing and hyperpolarizing components. J Neurosci 13:3252-3265. Medline

Sterzer P, Kleinschmidt A, Rees G (2009) The neural bases of multistable perception. Trends Cogn Sci 13:310-318. CrossRef Medline

Steuer R, Kurths J, Daub CO, Weise J, Selbig J (2002) The mutual information: detecting and evaluating dependencies between variables. Bioinformatics 18 [Suppl 2]:S231-S240.

Stoerig P, Cowey A (1997) Blindsight in man and monkey. Brain 120:535559. CrossRef Medline

Takahashi N, Oertner TG, Hegemann P, Larkum ME (2016) Active cortical dendrites modulate perception. Science 354:1587-1590. CrossRef Medline

Timofeev I, Grenier F, Bazhenov M, Sejnowski TJ, Steriade M (2000) Origin of slow cortical oscillations in deafferented cortical slabs. Cereb Cortex 10:1185-1199. CrossRef Medline

Timofeev I, Grenier F, Steriade M (2001) Disfacilitation and active inhibition in the neocortex during the natural sleep-wake cycle: an intracellular study. Proc Natl Acad Sci U S A 98:1924-1929. CrossRef Medline

Tong F (2003) Primary visual cortex and visual awareness. Nat Rev Neurosci 4:219-229. CrossRef Medline
Tononi G, Edelman GM (1998) Consciousness and complexity. Science 282:1846-1851. CrossRef Medline

Tononi G, Srinivasan R, Russell DP, Edelman GM (1998) Investigating neural correlates of conscious perception by frequency-tagged neuromagnetic responses. Proc Natl Acad Sci U S A 95:3198-3203. CrossRef Medline

Tononi G, Boly M, Massimini M, Koch C (2016) Integrated information theory: from consciousness to its physical substrate. Nat Rev Neurosci 17:450-461. CrossRef Medline

Tsuchiya N, Wilke M, Frässle S, Lamme VA (2015) No-report paradigms: extracting the true neural correlates of consciousness. Trends Cogn Sci 19:757-770. CrossRef Medline

Vanhaudenhuyse A, Noirhomme Q, Tshibanda LJ, Bruno MA, Boveroux P, Schnakers C, Soddu A, Perlbarg V, Ledoux D, Brichant JF, Moonen G, Maquet P, Greicius MD, Laureys S, Boly M (2010) Default network connectivity reflects the level of consciousness in non-communicative braindamaged patients. Brain 133:161-171. CrossRef Medline

Wardak C, Olivier E, Duhamel JR (2002) Saccadic target selection deficits after lateral intraparietal area inactivation in monkeys. J Neurosci 22: 9877-9884. Medline

Ward R, Danziger S, Owen V, Rafal R (2002) Deficits in spatial coding and feature binding following damage to spatiotopic maps in the human pulvinar. Nat Neurosci 5:99-100. CrossRef Medline

Weiskrantz L (1995) The problem of animal consciousness in relation to neuropsychology. Behav Brain Res 71:171-175. CrossRef Medline

Wilke M, Logothetis NK, Leopold DA (2003) Generalized flash suppression of salient visual targets. Neuron 39:1043-1052. CrossRef Medline

Wilke M, Mueller KM, Leopold DA (2009) Neural activity in the visual thalamus reflects perceptual suppression. Proc Natl Acad Sci U S A 106: 9465-9470. CrossRef Medline

Wilke M, Turchi J, Smith K, Mishkin M, Leopold DA (2010) Pulvinar inactivation disrupts selection of movement plans. J Neurosci 30:8650-8659. CrossRef Medline

Wilke M, Kagan I, Andersen RA (2012) Functional imaging reveals rapid reorganization of cortical activity after parietal inactivation in monkeys. Proc Natl Acad Sci U S A 109:8274-8279. CrossRef Medline

Wilke M, Kagan I, Andersen RA (2013) Effects of pulvinar inactivation on spatial decision-making between equal and asymmetric reward options. J Cogn Neurosci 25:1270-1283. CrossRef Medline

Winawer J, Parvizi J (2016) Linking electrical stimulation of human primary visual cortex, size of affected cortical area, neuronal responses, and subjective experience. Neuron 92:1213-1219. CrossRef Medline

Wu X, Zou Q, Hu J, Tang W, Mao Y, Gao L, Zhu J, Jin Y, Wu X, Lu L, Zhang Y, Zhang Y, Dai Z, Gao JH, Weng X, Zhou L, Northoff G, Giacino JT, He $\mathrm{Y}$, Yang Y (2015) Intrinsic functional connectivity patterns predict consciousness level and recovery outcome in acquired brain injury. J Neurosci 35:12932-12946. CrossRef Medline

Yarkoni T, Poldrack RA, Van Essen DC, Wager TD (2010) Cognitive neuroscience 2.0: building a cumulative science of human brain function. Trends Cogn Sci 14:489-496. CrossRef Medline

Zhang S, Xu M, Kamigaki T, Hoang Do JP, Chang WC, Jenvay S, Miyamichi K, Luo L, Dan Y (2014) Selective attention. Long-range and local circuits for top-down modulation of visual cortex processing. Science 345:660 665. CrossRef Medline

Zhou H, Schafer RJ, Desimone R (2016) Pulvinar-cortex interactions in vision and attention. Neuron 89:209-220. CrossRef Medline 